\title{
La fe como evento existencial- escatológico en el pensamiento de Rudolf Bultmann. De la filosofía de Martín Heidegger al planteo teológico
}

Alberto F. Roldán*

\section{Resumen}

En el presente artículo se analiza el planteo que el teólogo Rudolf Bultmann formula en torno al tema de la fe. Se exponen las influencias mutuas entre Martín Heidegger y el propio Bultmann a partir del trabajo conjunto que desarrollaron especialmente en Marburgo en los años 1923 y 1924. El autor pone de manifiesto que, si bien la filosofía existenciaria heideggeriana representó un influjo importante para Bultmann, este último desarrolla un planteo más teológico que caracteriza a la fe como un evento existencial y escatológico que exige la decisión de parte del oyente. Bultmann, además, se muestra fiel a su herencia luterana para tomar distancia del enfoque antropológico del existencialismo, afirmando el carácter total de la caída del ser humano que lo incapacita para alcanzar por sí mismo

\footnotetext{
Doctor en Teología por el Instituto Universitario Isedet de Buenos Aires y Máster en Ciencias Sociales y Humanidades por la Universidad Nacional de Quilmes (mención filosofía política). Cursó la Maestría en Educación en la Universidad del Salvador (Buenos Aires). Autor de unos veinte libros dentro del campo de su especialidad, con traducciones al portugués, inglés y alemán. Ha publicado decenas de artículos en revistas científicas. Ha sido profesor visitante y conferencista en universidades de América Latina, Estados Unidos, Europa y Corea del Sur. Director de posgrado del Instituto Teológico FIET y profesor y asesor del Programa Doctoral Latinoamericano de Ciencias Teológicas. Ha participado en jornadas de filosofía moderna organizadas por la cátedra respectiva de la Universidad Nacional de Mar del Plata. Es profesor adjunto de posgrado en teología de la Universidad Adventista del Plata en Entre Ríos, Argentina. Dirige la revista: Teología y cultura: www.teologos.com.ar. Contacto: alberto@teologos.com.ar.
} 
«la vida auténtica», dimensión que solo puede concretarse por medio de la fe en el Cristo crucificado. Este último constituye para Bultmann el verdadero escándalo del Evangelio y no el «falso escándalo» de la visión precientífica del kerigma neotestamentario. La presente investigación pretende demostrar que la desmitologización, que se torna en un escollo insalvable para muchos lectores de Bultmann, fue solo un método para facilitar la fe en el Evangelio por parte del hombre moderno. En consecuencia, y parafraseando a Immanuel Kant, Bultmann parece decir: «tuve que dejar de lado el mito para dar lugar a la fe».

\title{
Palabras clave
}

Bultmann, Heidegger, fe, evento.

\section{Faith as existential-eschatological event in the thought of Rudolf Bultmann. From the philosophy of Martin Heidegger to the theological approach}

\begin{abstract}
In this paper we analyze the proposition that the theologian Rudolf Bultmann made on the subject of faith. We describe the mutual influences between Martin Heidegger and Bultmann from specially developed joint work in Marburg in 1923 and 1924. The author shows that, although Heidegger's existential philosophy represented an important influence to Bultmann, the latter develops a more theological approach that characterizes faith as an existential and eschatological event that requires a decision on the part of the listener. Bultmann also remains faithful to its Lutheran heritage to take away the anthropological approach of existentialism, stating the total character of the fall of man that makes him unfit to achieve for itself «real life» dimension can be realized only by through faith in Christ crucified. The latter is for Bultmann the real scandal of the Gospel and not the «fake scandal» of the pre-scientific vision of the New Testament kerygma. This research aims to demonstrate that demythologizing, which becomes an insurmountable hurdle for many readers of Bultmann,
\end{abstract}


was just a method to facilitate faith in the gospel by modern man. Consequently, to paraphrase Immanuel Kant, Bultmann seems to say: «I had to let go of the myth to give rise to faith».

\title{
Key words
}

Bultmann, Heidegger, faith, event.

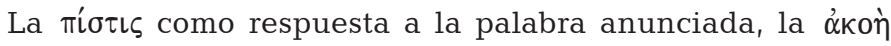

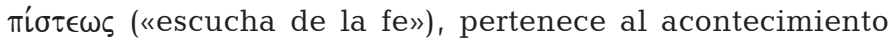
salvífico, al acontecimiento escatológico. Es, como posibilidad, el nuevo camino de salvación.... ${ }^{1}$.

La teología busca una interpretación más originaria del ser del hombre en relación a Dios, esbozada a partir del sentido de la fe misma y atenida a ella ${ }^{2}$.

Bultmann "pone de manifiesto» de algún modo en teología la atención filosófica de Heidegger a la experiencia facticial y su carácter histórico, pero ello, aún más y mejor que el modelo a partir del cual Heidegger se pregunta por la vida facticial, y esto es, se ha señalado, la experiencia cristiana... ${ }^{3}$.
\end{abstract}

\section{Introducción}

La fe es el acontecimiento central de la experiencia religiosa en general y cristiana en particular. Es también aquel ámbito subjetivo de la persona humana que, tal vez, sea inexpugnable al cuestionamiento científico y filosófico. Por eso es importante indagar sobre su carácter y contenido. En el presente artículo nos proponemos analizar el carácter existencial-escatológico de la fe en el pensamiento del teólogo luterano Rudolf Bultmann. Antes de indicar la metodología que utilizaremos para ese análisis es oportuno hacer una deconstrucción de cierto preconcepto, en el sentido negativo del término, en cuanto a la teología de Bultmann. Porque su nombre

1 Rudolf Bultmann, Teología del Nuevo Testamento, trad. Víctor A. Martínez de Lapera (Salamanca: Sígueme, 1981), 389. Cursivas originales.

2 Martin Heidegger, Ser y tiempo, trad. Jorge Eduardo Rivera (Madrid: Editora Nacional, 2002), $\xi 3$, 20-21. Cursivas originales.

3 Philippe Capelle-Dumont, Filosofía y teología en el pensamiento de Martin Heidegger, trad. Pablo Corona (Buenos Aires: FCE, 2012), 233. 
siempre se lo ha vinculado casi exclusivamente con su propuesta de «desmitologización» o «desmitización» del Nuevo Testamento 4 . Pero, como bien señala Joseph Florkowski, «el proyecto de Bultmann no es la desmitologización dictada por la mentalidad científica moderna. No es tampoco la constitución de una hermenéuica de la Escritura o de la existencia injertada pura y simplemente en Heidegger. Bultmann quiere decir lo que es creer. Y ello, dentro mismo de la fe» ${ }^{5}$. Un repaso somero de las obras y artículos escritos por Rudolf Bultmann muestra claramente que no es su tema central la demitologización del kerigma, sino que en todo caso ese proceso debe estar al servicio de la fe.

Procederemos del siguiente modo: en la primera parte, exponemos la influencia que la filosofía de Heidegger ejerció en el teólogo luterano, en la segunda, analizamos el tema de la fe como exigencia y decisión, en la tercera parte estudiamos el modo en que Bultmann define a la fe como acto escatológico, para finalizar con una evaluación crítica de su pensamiento sobre el tema. En la cuarta sección se procura establecer hasta qué punto el carácter existencial, que Bultmann le otorga a la fe, es heredero de la filosofía existenciaria ${ }^{6}$

El tema de la «desmitologización» o «desmitización» del Nuevo Testamento alude al proyecto de Bultmann de expurgar al kerigma neotestamentario de la «mitología» entendida en los términos de un lenguaje precientífico en el que está inserto ese kerigma. Algunos textos donde expone el proyecto son: Nuevo Testamento y mitología, trad. Antonio Bonnano (Buenos Aires: Almagesto, 1998), el artículo «Jesucristo y la mitología» en John Bowden y James Richmond, Antología de teólogos contemporáneos, trad. José Luis Lana (Barcelona: Kairós, 1967), 45-54 y Kerygma und Mythos (Hamburg: Reich \& Heidrich, 1960). Uno de los mejores estudios filosóficos al planteo de Bultmann es el capítulo de Paul Ricoeur, «Prefacio a Bultmann», en El conflicto de las interpretaciones, trad. Alejandrina Falcón (Buenos Aires: FCE, 2003).

5 Joseph Florkowski, La teología de la fe en Bultmann, trad. D. Eloy Requena (Madrid: Stvdivm 1973), 7.

6 Decimos «existenciaria» y no «existencialista» porque el propio Heidegger se ocupa de aclarar que su enfoque no es meramente el existencialista, heredero de Kierkegaard. Para el existencialismo, el tema central es el ser humano, mientras que lo que plantea Heidegger es la búsqueda o indagación por el «ser». El propio Heidegger lo aclara en una nota que introduce en Ser y Tiempo: «En el siglo XIX S. Kierkegaard abordó expresamente el problema de la existencia en cuanto problema existentivo y lo pensó con profundidad. Sin embargo, la problemática existencial le es de tal modo ajena, que, desde un punto de vista ontológico, Kierkegaard es enteramente tributario de Hegel y de la filosofía antigua vista a través de él. De ahí que filosóficamente haya más que aprender de sus escritos "edificantes" que de los teoréticos, con la excepción del tratado sobre el concepto de la angustia». Ser y Tiempo, op. cit., parágrafo $\xi 45$, nota 6. También Alejandro Vallés comenta que cae la crítica del existencialismo cuando dice que ella «ha vuelto corriente un equívoco acerca del autor de El Ser y el Tiempo: el de considerarlo un mero investigador del problema de la existencia humana (...) Heidegger insiste en precisar que su preocupación fundamental no es otra que la de fundar válidamente la ontología, la ciencia del ser». Nota preliminar a Martín Heidegger, ¿Qué es metafísica? Trad. Xavier Zubiri (Buenos Aires: Ediciones Alpe, 1955), 9-10. Cursivas originales. También Carlos Astrada define la filosofía de Heidegger en el sentido óntico. Dice: «Sin duda, el punto de partida del 
de Martin Heidegger y en qué aspectos el trabajo del exégeta luterano significa una toma de distancia de esa filosofía. Finalizamos con una conclusión que resume la investigación realizada.

\section{El influjo de la filosofía "existenciaria» de Heidegger en el pensamiento de Bultmann}

No hay dudas de que la filosofía existenciaria de Heidegger ha servido de inspiración para que Bultmann desarrolle su teología y su comprensión de la fe. Philippe Capelle-Dumont ofrece datos importantes sobre el encuentro entre Heidegger y Bultmann. Ocurrió en 1923 cuando Heidegger es instalado como profesor extraordinario en la Universidad de Marburgo. Allí se respiraba un ambiente protestante y su aprecio por el exégeta luterano era tan manifiesto que, en carta enviada a Karl Jaspers el 13 de junio de 1924, dice: «Afuera es magnífico; en la universidad no ocurre nada, ningún estímulo. El único ser humano es el teólogo Bultmann, con quien me encuentro cada semana» ${ }^{7}$.

John Macquarrie, en su estudio comparativo entre Heidegger y Bultmann, explica que este último reclama una especial relación del teólogo con la filosofía existencialista. Esa adopción del existencialismo, en palabras del propio Bultmann «es completa y simplemente que la tarea filosófica que se esfuerza por desarrollar en conceptos apropiados la comprensión de la existencia que está dada con la existencia humana» ${ }^{8}$.

filosofar heideggeriano es existentivo, porque tal cual se lo reconoce en la Introducción de Sein und Zeit, la cuestión de la existencia (ec-sistencia) es una "oportunidad" óntica del Dasein, vale decir que sobre la base de esta oportunidad, solo dada al hombre, este se lanza a la aventura metafísica del ser». Carlos Astrada, Heidegger. De la analítica ontológica a la dimensión dialéctica (Buenos Aires: Quadrata, 2003), 15. Cursivas originales. Para Dina Picotti, el planteo de Heidegger por la historia del ser y la hermenéutica, «equivale a la superación de la metafísica o del pensar por el fundamento, en cuanto desemboca en un punto de partida y ámbito no explicable por fundamento alguno sino solo aclarable por su propio darse o sustraerse». Dina Picotti, Heidegger. Una interpretación (Buenos Aires: Cuadrata, 2010), 22.

7 Carta referida por Hermann Mörchen, incluida en B. Jaspert, comp., Rudolf Bultmann Werk un Wirkung, cit. por Philippe Capelle-Dumont, op. cit., 230. Por su parte Jean Greisch, que ha realizado una profunda interpretación de la conferencia de Heidegger «Fenomenología y teología», destaca la importancia que la teología tuvo para Heidegger en su período en Marburgo, no solo porque estuvo marcado por encuentros con teólogos como Paul Tillich y, sobre todo, Bultmann, «sino también con estudiantes interesados por una problemática teológica, como Hans Jonas o Hanna Arendt». La invención de la diferencia ontológica. Heidegger después de Ser y Tiempo, trad. Julián Fava (Buenos Aires: Las Cuarenta, 2010), 19.

8 Rudolf Bultmann, Kerygma und Mythos, vol. II, op. cit., 192, cit. por John Macquarrie, An Existencialit Theology. A Comparison of Heidegger and Bultmann (Londres: SCM Press, 1955), 10. 
En su obra Nuevo Testamento y mitología Bultmann da cuenta, a modo de comparación, que así como Jaspers no ha tenido problemas en incorporar o transponer la interpretación de Kierkegaard del ser cristiano a su filosofía, también es legítimo apelar al análisis que Heidegger hace del Dasein. Dice:

(...) el análisis del Dasein (es decir, del ser del hombre) parecería no ser más que una versión secularizada y filosófica de la visión de la vida humana en el Nuevo Testamento. Para él, la principal característica del ser del hombre en la historia es la angustia. El hombre existe en una tensión permanente entre el pasado y el futuro. En cada momento se ve enfrentado a una alternativa. Se debe sumergir en el mundo natural concreto, perdiendo así inevitablemente su individualidad, o debe abandonar toda seguridad y entregarse sin reservas al futuro, y así lograr solo su ser auténtico. ¿ No es este exactamente el entendimiento de la vida humana del Nuevo Testamento? ${ }^{9}$.

A quienes piensan que Bultmann está forzando las categorías heideggerianas para hacerlas coincidir con el Nuevo Testamento, el exégeta luterano invierte la carga de la prueba para sostener que

Rudolf Bultmann, Nuevo Testamento y mitología, op. cit., 40-41. El término Dasein, clave en la filosofía de Heidegger, es una manera de referirse al ser humano en el mundo. En palabras de Ricardo Etchegaray: «Heidegger prefiere el término Dasein al concepto de "hombre", porque este último está asociado a la concepción moderna en la que se lo define como "ser racional", como "ser conciente" o como "subjetividad". Heidegger parte, entonces, de la comprensión como existenciario o modo de ser del Dasein (del ser humano), en tanto está en el mundo con los entes que están delante (objetos) o que están a la mano (útiles) y con los otros existentes (seres humanos)». Introducción a los modelos de pensamiento dialéctico, fenomenológico, hermenéutico y existencial (Buenos Aires-San Justo: Universidad Nacional de La Matanza y Prometeo libros, 2007), 120. Por su parte, John Macquarrie distingue tres aspectos de la estructura del Dasein: a. El Dasein como lo que está delante como posibilidad, proyecto, comprensión; b. el Dasein como algo que ya está-en-el-mundo y que pertenece al fenómeno de la facticidad; c. el Dasein que está unido al mundo, tanto que es absorbido por él, es el fenómeno de la caída. John Macquarrie, Martin Heidegger (Londres: Lutterworth Press, 1968). 27. Sobre el «estar-en-el-mundo», dice Heidegger: «Comprensión del ser y pro-yecto, a saber icomo arrojado! El ser-en-el-mundo del ser ahí». Aportes a la filosofía. Acerca del evento, trad. Dina V. Picotti C. (Buenos Aires: Biblos, 2006), 241. Cursivas originales. En cuanto a la «facticidad» Heidegger dice: «es el nombre que le damos al carácter de ser de "nuestro" existir "propio". Más exactamente, la expresión significa: ese existir en cada ocasión (fenómeno de la "ocasionalidad" (...)» Martín Heidegger, Ontología. Hermenéutica de la facticidad, trad. Jaime Aspiunza (Madrid: Editora Nacional, 2003), 15. Cursivas originales. Luego de hacer un repaso crítico de la historia de la hermenéutica desde Aristóteles, pasando por Filón y San Agustín, indicando que es en el siglo XVII cuando la hermenéutica ya no es la interpretación misma, sino las condiciones de posibilidad de los medios de la comunicación y la interpretación, propone como definición: «El término hermenéutica pretende indicar el modo unitario de abordar, plantear, acceder a ella, cuestionar y explicar la facticidad». Ibíd., 17. Y: «La hermenéutica tiene por objeto temático el existir propio en cada ocasión (...)», Ibid., 35. 
«uno debería sorprenderse de que la filosofía esté diciendo lo mismo que el Nuevo Testamento, y que lo diga con suma independencia» ${ }^{10}$. Comenta luego un libro de Wilhelm Kamlah, aparecido en la época en que Bultmann escribe su obra, en el cual se analiza el tema de la fe ${ }^{11}$. Bultmann aclara que el planteo de Kamalah es filosófico y rechaza el carácter escatológico del entendimiento cristiano del ser, entendiendo mal el concepto de «separación del mundo» sin captar su carácter dialéctico. Kamalah habla del «autocompromiso» y de la «emancipación». Con esas ideas es consciente de que se acerca, tal vez inconscientemente, a la concepción cristiana de la fe. Y se hace eco de una pregunta muy habitual para aquella época y, añadimos, también para la nuestra, que se resume en plantear cómo se puede llegar a la fe si esta es un don de Dios y no se obtiene por esfuerzo humano. Desde esa problemática, Bultmann formula una pregunta y ensaya una respuesta: «iEs la fe, en este sentido, la disposición natural del hombre?. Sí y no. Sí, porque la fe no es una cualidad sobrenatural misteriosa, sino la disposición de la humanidad genuina ${ }^{12}$. Bultmann no duda en afirmar que la filosofía moderna, léase el existencialismo, tiene una deuda con el Nuevo Testamento, con Lutero y Kierkegaard en cuanto a la naturaleza humana. Y ello le permite decir que «el mismo hecho de que sea posible producir una versión secularizada del concepto de fe del Nuevo Testamento demuestra que no hay nada misterioso ni sobrenatural en la vida cristiana» ${ }^{13}$. Aunque se puede percibir el aprecio que Bultmann expresa hacia el existencialismo, toma distancia del mismo al decir que «estos filósofos están convencidos de que todo cuanto necesitamos es que nos informen sobre la "naturaleza" del hombre para poder realizarla» ${ }^{14}$. Pero el Nuevo Testamento, aunque no nos

10 Rudolf Bultmann, Nuevo Testamento y mitología, op. cit., 41. En el ensayo «The Historicity of Man and Faith», Bultmann reconoce explícitamente su identificación con la filosofía de Heidegger. Al responder a las críticas a su pensamiento, formuladas por Gerhardt Kuhlmann y, con referencia específica al término «futuro» en el cual la teología de Bultmann comprende que es idéntico a lo que Heidegger descubre como una auténtica posibilidad de ser, Bultmann reafirma que coincide con ese planteo tanto desde el punto de vista formal como ontológico. Rudolf Bultmann, Existence \& Faith. Shorter Writings of Rudolf Bultmann, trad. Schubert M. Ogden (Nueva York: Living Age Books, 1960), 96-97.

11 Se refiere a Wilhelm Kamlah, Christentum und Selbsbehauptung (Francfort: Vittorio Klostermann, 1940).

12 Rudolf Bultmann, Nuevo Testamento y mitología, op. cit., 43.

13 Ibid., 44.

14 Ibíd., 44-45. 
ofrece una doctrina de la naturaleza auténtica del hombre: «proclama el acontecimiento de la redención que fue hecho en Cristo. (...) dice que sin ese acto salvador de Dios nuestra situación es desesperada, una afirmación que repudia el existencialismo» ${ }^{15}$.

En su comparación entre Heidegger y Bultmann, John Macquarrie afirma la íntima relación entre ambos pensadores. Cita la declaración de Heidegger en cuanto a la teología en estos términos:

La teología busca una interpretación más originaria del ser del hombre en relación a Dios, esbozada a partir del sentido de la fe misma y atenida a ella. Poco a poco empieza a comprender nuevamente la visión de Lutero de que la sistematización dogmática de la teología reposa sobre un «fundamento» que no viene primariamente de un cuestionar interno a la fe, y cuyo aparato conceptual no solo es insuficiente para responder a la problemática teológica, sino que, además, la encubre y desfigura ${ }^{16}$.

A partir de esa cita de Heidegger, Macquarrie comenta que fue Bultmann quien tomó el desafío planteado por el filósofo alemán y que, antes de proceder a la interpretación de lo que está contenido en la fe cristiana, Bultmann examinó las presuposiciones del pensamiento teológico.

Y llegó a creer que esas presuposiciones están clarificadas y aseguradas por una filosofía de tipo existencial. Porque el existencialismo es una filosofía del ser. (...) no es una filosofía especulativa sino un análisis de la comprensión de la existencia que está dada con la existencia ${ }^{17}$.

Para Macquarrie, la influencia del existencialismo heideggeriano en la teología de Bultmann no es algo externo semejante a un sistema metafísico. Se trata de una influencia que define como intrínseca ya que es «una búsqueda pre-teológica u ontológica en la idea del ser, la cual la teología da por sentado» ${ }^{18}$. Macquarrie también encuentra otro punto de conexión entre la filosofía de Heidegger y el pensamiento

\footnotetext{
15 Ibíd., 45.

16 Martin Heidegger, Ser y tiempo, op. cit., $\xi 3,20-21$. Cursivas originales.

17 John Macquarrie, An Existencialist Theology. A Comparison of Heidegger and Bultmann, op. cit., 8.

18 Ibid., 9.
} 
de Bultmann. En su teología del Nuevo Testamento Bultmann ve una variedad de teologías, que tienen terminologías y énfasis diferentes, pero de ellas, da prominencia a la teología paulina que expone la doctrina del ser humano. Del mismo modo, adopta las distinciones heideggerianas en cuanto a la existencia. Dice Bultmann:

Esa exposición deriva en dos partes -la vida del hombre sin Cristo y la vida del hombre en la fe cristiana-. De un modo similar, Heidegger en la exposición de su filosofía, describe primero lo que él denomina existencia diaria o inauténtica, y luego va hacia el problema de una existencia auténtica ${ }^{19}$.

Por su parte, Luis Maldonado señala que la estructura del pensamiento de Bultmann es «circular-involutivo». Explica:

(...) se mueve en la bipolaridad de lo implícito y lo explícito (precomprensión y comprensión). Esto no es casualidad sino influencia directa que Bultmann recibe de Heidegger en la época feliz de su coincidencia y convivencia en Marburg, cuando los dos organizaban seminarios conjuntamente, antes aún de la aparición sonada de El ser y el tiempo $(1927)^{20}$

Otro aspecto donde Maldonado observa la influencia de Heidegger en Bultmann es el referido a la comprensión y autocomprensión del hombre, las cuales derivan en la «vida auténtica». Y agrega: «Su autenticidad consistirá en abrirse plenamente a ellas, aceptarlas

19 Ibid., 26. Si bien la «vida auténtica» es un lenguaje que remite a Heidegger, es oportuno consignar la aclaración de Vattimo cuando, al interpretar a Heidegger, dice: «La cuestión de la autenticidad no es un mero problema "ético" o "psicológico" de este ente particular que es el ser-ahí. Las cosas, los objetos, el mundo en su conjunto, ya para Ser y tiempo, vienen al ser, se dan como entes, solo en cuanto es el ser-ahí, que abre el horizonte de su darse. Por lo tanto, no hay ser fuera o antes, o independientemente, del proyecto arrojado que es el ser-ahí es». Gianni Vattimo, Ética de la interpretación, trad. Teresa Oñate (Barcelona: Paidós Ibérica, 1991), 134. Cursivas originales. Para Agamben, el Dasein heideggeriano describe la inquietud y el movimiento de ser-en-el-mundo, del estar-ahí, en el lugar propio. Giorgio Agamben, Teología y lenguaje. Del poder de Dios al juego de los niños, trad. Matías Raia (Buenos Aires: Las Cuarenta, 2012), 30.

20 Luis Maldonado, El menester de la predicación (Salamanca: Sígueme, 1972), 40. Cursivas originales. Maldonado cuenta que en un encuentro con Heidegger acontecido en el año 1956, el filósofo alemán le comentó que, en su opinión, la empresa que había encarado Bultmann era de similar envergadura a la que llevó a cabo Santo Tomás con el aristotelismo, «Bultmann había querido incorporar las categorías forjadas por el existencialismo para vertebrar, articular, elucidar la teología contemporánea». Ibid., 42. 
decididamente; es decidir así su existencia (decisión existencial). Así pasa de la precomprensión a la plena comprensión de sí. Eso es la fe»» ${ }^{21}$.

Es oportuno tomar en cuenta la vinculación que pudiera existir entre Heidegger y Bultmann respecto al tema de la fe. ¿En qué aspectos Bultmann ha sido influido por Heidegger para desarrollar su teología de la fe? Por otra parte, ¿̇se ha referido Heidegger a la fe? En caso positivo, żen qué sentido lo ha hecho? El propio Heidegger admitió que el primer impulso para su filosofía procedió de la teología cristiana. Formado inicialmente en la teología católica, giró después a la teología protestante influido por el pensamiento de Lutero. Reflexionando a partir del relato de Juan 3, donde hay un diálogo entre Jesús y Nicodemo, Heidegger vincula a la fe con el renacimiento. El «creer» es, entonces, la "posibilidad de existir en la modalidad de creyente [Y define] La fe, por lo tanto, solo se comprende siempre a sí misma como creyente» ${ }^{22}$. Y agrega: «Creer es existir en la inteligencia que cree en la historia revelada, es decir, que se consuma con el Crucificado» ${ }^{23}$. En el semestre invernal de 1920-1921, Heidegger ofrece un curso sobre «fenomenología de la religión». Una las exposiciones se refiere al pensamiento de San Pablo en la carta a los gálatas, que Heidegger interpreta desde una óptica fenomenológica. Comenta a propósito de Gálatas 3.2:

San Pablo pone todo su argumento principal teológico en la balanza: Abraham mismo se justifica solo por la fe. ¿̇Cómo se las ha [sic], por tanto, con

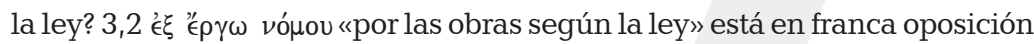

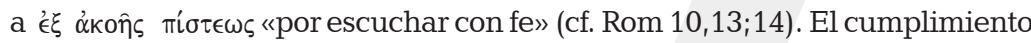
de la ley es imposible, cada uno fracasa en ello, solo la fe justifica ${ }^{24}$.

21 Ídem. El tema de la precomprensión, enunciado por Heidegger en Ser y tiempo, es adoptado por Bultmann y Gadamer. El primero, adopta el enfoque heideggeriano de la precomprensión cuando señala: «El hecho de que la predicación cristiana cuando se encuentra con el hombre pueda ser comprendida por él, demuestra que posee una precomprensión de ella». Rudolf Bultmann, «El problema de la "teología natural"», en Creer y comprender, vol. I, trad. D. Eloy Requena (Madrid: Stvdivm, 1974), 256. Sobre la exposición del tema en la hermenéutica de Gadamer, véase Alberto F. Roldán, «La reivindicación del prejuicio como precomprensión en la teoría hermenéutica de Gadamer», Enfoques 1, año XXIV, (2012): 19-29.

22 Martín Heidegger, Wegmarken (Fránfort del Meno: Klostermann, 1978), 53. Cit. por Philippe Capelle-Dumont, op. cit., 36.

23 Cit. en Ibid., 37.

24 Martín Heidegger, Fenomenología de la religión, trad. Jorge Uscatescu (México: Ediciones SiruelaFCE, 2006), 98. 
Se trata de una interpretación que podríamos denominar «luterana» $\mathrm{y}$, por lo tanto, coincidente con lo que veremos más adelante en cuanto a Bultmann. Pero esa sería solo una fase «teológica» del pensamiento de Heidegger. Porque, al fin de cuentas y como demuestra Capelle-Dumont, Heidegger advierte que no hay que confundir teología con filosofía o aún pretender elaborar una «filosofía de la fe». En todo caso, puede haber una "ciencia de la fe» ${ }^{25}$ bajo cuatro aspectos: a. ciencia que es develada en la fe, es decir, «de lo que es creído»; b. ciencia del comportamiento del creyente y de su creencia; c. ciencia que se inscribe en el gesto de la fe, que es su propio origen y d. ciencia de la fe en tanto «contribuye, por su parte, a conformar la creencia [fidelité] ${ }^{26}$. Heidegger admite cierta sistematicidad en la teología, pero no en el sentido de poder elaborar un sistema de pensamiento similar a lo que puede hacerse con la filosofía. Sino que solamente se trata de un «sistema de la fe» y ello se materializa en un modo circular: «La teología solo es sistemática si es históricopráctica. Solo es histórica si es sistemático-práctica. Solo es práctica si es sistemático-histórica» ${ }^{27}$.

En síntesis, la teología debe estar al servicio de la existencia creyente. «De la fe a la fe, para y por la creencia [fidelité]» ${ }^{28}$. Pero este reconocimiento de la importancia central de la fe, por parte de Heidegger, no significa que pueda hacerse de ella el centro de un reflexionar filosófico. Porque la teología no es ni filosofía de la religión ni psicología de la religión ni, mucho menos, «teología filosófica» ya que «la teología cristiana está fundada, primera y principalmente, por la fe, y solo de ella toma los recursos propios de su metodología» ${ }^{29}$. En todo caso, la teología necesita de la filosofía como una especie de herramienta correctiva de sus conceptos fundamentales. La filosofía ya no volverá a ser la «sierva» (ancilla) de la teología, como lo fue en la Edad

Escribimos la palabra «ciencia» entre comillas, porque el propio Heidegger, en términos estrictos, no aceptaba el carácter científico de la teología. En carta que escribe como respuesta a una misiva enviada por Elizabeth Blochmann como resultado de su conferencia «Fenomenología y teología» dice: «La cuestión de saber si la teología es una ciencia surgió en el curso de la discusión y, en Marburgo como siempre, delante de mis alumnos. Aunque si personalmente yo estoy convencido de que la teología no es una ciencia, no estoy actualmente todavía en condiciones de mostrarlo efectivamente». Cit. por Jean Greisch, op. cit., 29. Cursivas originales.

26 Philippe Capelle-Dumont, op. cit., 38.

27 Ibíd., 40. Cursivas originales.

28 Ibíd., 39.

29 Ibíd., 41 
Media, porque «lejos de volver a convertirse en "sierva" de la teología, lleva a cabo la remisión crítica de la teología a una conceptualidad adecuada $»^{30}$. La teología debe atenerse a su propio tema: la fe. Por el contrario, la filosofía «no depende de ninguna necesidad teológica, debe librarse a su propia aventura y a su preguntar "inactual"» ${ }^{31}$. Esta distinción entre filosofía y teología era fuertemente mantenida por Heidegger. El hecho se refleja en una carta fechada el 31 de diciembre de 1927. Su contenido es una respuesta de Heidegger a una consulta de Bultmann, quien debía escribir un breve artículo sobre Heidegger para un diccionario. Luego de expresar su sorpresa, ya que dice que él apenas comienza «a andar a gatas», escribe Heidegger:

En cuanto al contenido habría que decir solamente que mi trabajo tiende a una radicalización de la ontología antigua y simultáneamente a una ampliación universal de la misma en relación con la región de la historia. Constituye el fundamento de esta problemática la partida del «sujeto», en el bien entendido sentido del Dasein humano, de modo que con la radicalización de este enfoque obtienen a la vez su derecho los auténticos motivos del Idealismo Alemán. Agustín, Lutero, Kierkegaard son esenciales filosóficamente para la formación de una comprensión más radical del Dasein, lo mismo que Dilthey lo es para la interpretación del «mundo histórico», y Aristóteles y la Escolástica lo son para la formulación rigurosa de ciertos problemas ontológicos. Pretendo conseguir todo eso con un método propio y guiado por la idea de una filosofía científica, tal como la fundó Husserl ${ }^{32}$.

Se podría decir que esta es una síntesis programática de lo que pretendía Heidegger: elaborar una filosofía que implicara una radi-

Ibíd., 44. En la conclusión de su análisis de la conferencia de Heidegger «Fenomenología y teología», Jean Greisch dice que para Heidegger, en ningún caso, la teología podría anexarse a la fenomenología ni podría haber un giro teológico de la fenomenología o un giro fenomenológico de la teología porque «el único espacio de reencuentro posible entre la filosofía y la teología es, para Heidegger, el de una ontología fenomenológica» op. cit., 65. En ese sentido, la filosofía representa el correctivo de los conceptos ontológicos fundamentales de los que también trata la teología. En otro texto de Heidegger que se titula Hitos, el filósofo alemán dice de la teología: «siendo absolutamente diferente a la filosofía, se relaciona con esta. Se sigue de nuestra tesis que la teología como ciencia positiva es fundamentalmente más próxima a la química y a las matemáticas que a la filosofía. De este modo formulamos, en su forma extrema, la relación de la Teología con la Filosofía», Martín Heidegger, Wegmarken, op. cit., 49. Traducción española: Hitos, Trad. H. Cortés Gabaudán y A. Leyte Coello (Madrid: Alianza, 2000), cit. por Philippe Capelle-Dumont, op. cit., 27.

31 Philippe Capelle-Dumont, op. cit., 47. Cursivas originales.

32 Andreas Gromann y Christof Lanmesser (edit.), Rudolf Bultmann/Martin Heidegger, Correspondencia 1925-1975, trad. Raúl Gabás (Barcelona: Herder, 2012), 37. 
calización de la ontología antigua, centrada en el Dasein y en la cual Agustín, Lutero, Kierkegaard, Dilthey y su maestro Husserl fueran referentes fundamentales.

Otro aspecto de punto de contacto entre Heidegger y Bultmann es el círculo hermenéutico y, como parte del mismo, la precomprensión en tanto momento de la operación hermenéutica. En su ensayo «El problema de la hermenéutica», Bultmann expresa la importancia que el pensamiento de Heidegger ha alcanzado en ese campo. Dice:

\begin{abstract}
El problema de la hermenéutica ha adquirido una claridad decisiva al presentar Heidegger la comprensión como algo existencial, y a través de su análisis de la interpretación, como desarrollo de la comprensión; pero, sobre todo, gracias a su análisis del problema de la historia y de su interpretación de la historicidad del pensamiento ${ }^{33}$.
\end{abstract}

Como hemos expuesto en otro artículo ${ }^{34}$, el propio Heidegger afirmó: «La comprensión del ser es, ella misma, una determinación de ser del Dasein» ${ }^{35}$. En nota al pie y, para despejar toda duda, Heidegger aclara: «Pero, ser, aquí, no solo en cuanto ser del hombre (existencia). Esto resultará claro por lo que sigue. El estar-en-el- mundo encierra en sí la relación de la existencia con el ser en total: comprensión del ser ${ }^{36}$. Se trata, tal como lo interpreta Hans-Georg Gadamer, de ser

33 Rudolf Bultmann, «El problema de la hermenéutica» en Creer y comprender II, op. cit., 187. En la parte final de ese ensayo, Bultmann arremete contra Karl Barth que en Die kirchliche Dogmatik III.2, rechaza la opinión de que un enunciado teológico solo pueda ser válido como elemento de la comprensión cristiana de la existencia humana y que, si bien los enunciados teológicos se refieren a la existencia humana, no lo son originalmente. Originalmente, argumenta Barth, se trata de hechos que determinan el ser y la acción de Dios que no se los puede reducir a «enunciados sobre la vida interior del hombre». Es la última frase la que parece molestar más a Bultmann porque, dice: «traiciona la total incomprensión de lo que es interpretación existencial y del sentido de la existencia indicado en ella. Esta no es en absoluto la "vida interior del hombre", que se puede tener ante los ojos prescindiendo de lo distinto de ella y de lo que le sale al encuentro (sea entorno, semejantes o Dios)», Ibíd., 193. Y finaliza su crítica sobre «el don de la fe» tal como es planteado por Barth, preguntando, entre otras cosas: ¿̇cómo penetran los acontecimientos históricos en el campo visual del creyente? Y ícómo distinguir semejante fe de una ciega aceptación por medio de un sacrificium intellectus? Responde: «Preguntar por un sentido válido de la imagen mítica del mundo es precisamente la intención de mi interpretación existencial del mito, y con ello intento proceder metódicamente», Ibíd., 194.

34 Alberto F. Roldán, «La reivindicación del prejuicio como precomprensión en la teoría hermenéutica de Gadamer», op. cit., 19-29.

35 Martín Heidegger, Ser y tiempo,op. cit., § 4, 23. Cursivas originales.

36 Ibíd., nota a. Cursivas originales. 
conscientes de los prejuicios entendidos como "precomprensiones» con que llegamos a «la cosa misma» de un texto.

Habiendo expuesto, a grandes rasgos, la influencia que Heidegger ejerció en Bultmann, pasamos ahora a analizar su exposición sobre la fe.

\section{La fe como exigencia y decisión}

En el parágrafo $\xi 35$ de su Teología del Nuevo Testamento, Bultmann hace un pormenorizado análisis de la estructura de la

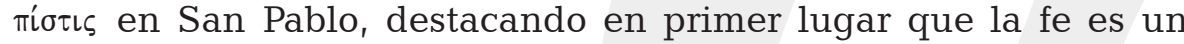
acto de obediencia, según se desprende del texto de Romanos 1,5. Es acto de obediencia por cuanto «se basa en que el mensaje, que exige el reconocimiento del Crucificado como el kúpıos, exige de los hombres el abandono de la manera anterior que tenían de entenderse a sí mismos $(\ldots) »^{37}$. Allí mismo, aclara que esa obediencia de la fe es la auténtica obediencia que exigía la ley de Dios, pero que los judíos no habían interpretado bien, ya que buscaban labrar su propia justificación por sí mismos. Hay, además, un segundo malentendido que sostiene que la fe es una especie de «experiencia» o de «virtud». «No es -como un perfecto estado del alma- la salvación misma, sino que, en cuanto obediencia auténtica, es la condición para recibir la

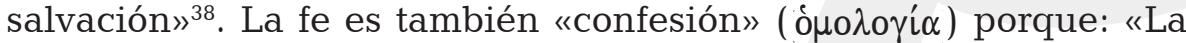

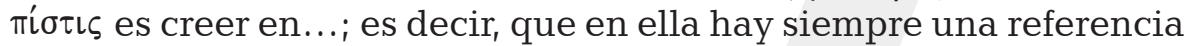
a su objeto, a la acción salvífica de Dios en Cristo» ${ }^{39}$.

Luego, Bultmann relaciona la fe con la comprensión. Dice:

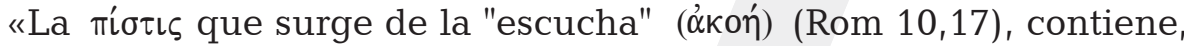
por tanto, de manera necesaria, un saber. Por ello puede a veces hablar Pablo como el saber fundamentase la fe $»^{40}$. A partir de los textos de 1 Tesalonicenses 5,2 - Romanos 6,3 - 2 Corintios 5,1 y 8,9

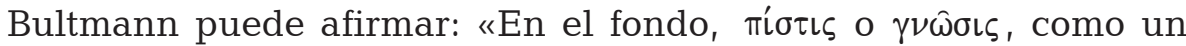
nuevo entenderse a sí mismo (...) $»^{41}$. Apelando a Filipenses 3, 8-10,

\footnotetext{
37 Rudolf Bultmann, Teología del Nuevo Testamento, op. cit., 374.

38 Ibíd., 375

39 Ibíd., 376.

$40 \quad$ Ibíd., 377.

41 Ibíd., Cursivas originales.
} 
Bultmann relaciona el conocimiento del ser humano hacia Dios y de Dios hacia el ser humano. Dice: «Se aclara totalmente el sentido de $\pi i \sigma \tau \iota \varsigma$ en el hecho de que el conocer $(\gamma \iota \nu \hat{\omega} \sigma \kappa \epsilon \iota \nu)$ humano tiene

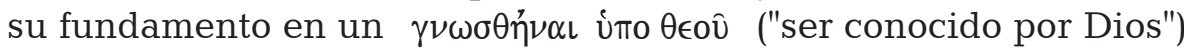
(Gál 4,9; 1 Cor 13,12)»².

Por último, la fe se relaciona con la esperanza. «En el hecho de

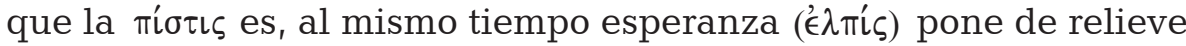
que el creyente está orientado a un punto fuera de sí mismo» ${ }^{43}$. Esto significa «un estar libre y abierto al futuro, ya que el creyente abandona en la obediencia a Dios la preocupación por sí mismo y la preocupación por su futuro» ${ }^{44}$. Citando el famoso binomio de Oscar Cullmann, Bultmann vuelve al tema de la decisión, señalando:

\footnotetext{
El ser del creyente es el movimiento entre el «ya»y el «todavía no». «Ya»: la decisión de la fe ha liquidado el pasado; debe ser consolidada como auténtica decisión, es decir, debe ser realizada siempre de nuevo. Como algo superado, el pasado se halla siempre presente y la fe debe recordar el pasado como algo que amenaza continuamente ${ }^{45}$.
}

En su perspectiva existencial, el acto de fe no es, para Bultmann, algo puntual sino que, debido a que el cristiano vive entre los tiempos, su ya de decisión, si bien ha liquidado el pasado, para que alcance la plena autenticidad deberá ser siempre realizada de nuevo. De otro modo, la fe puede sentirse amenazada por ese pasado que se supone superado.

Para Bultmann, la decisión de fe no es algo que acaece por virtud humana ya que «el creyente puede entender su decisión, cuya posibilidad experimenta él como gracia, únicamente como don de la gracia $»^{46}$. Por un momento, Bultmann menciona tangencialmente el tema de la predestinación y la elección a partir de los textos de Filipenses 1,29; Romanos 8,29 y 9,6-29 para acentuar la iniciativa divina en el acto de fe. «La fe es activada por Dios en cuanto que,

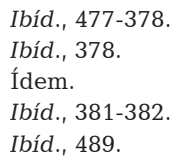


como gracia que antecede, posibilita la decisión del hombre, de manera que esta únicamente puede entenderse a sí misma como regalo de Dios, sin perder por ello su carácter de decisión $»^{47}$.

\section{La fe como existencia escatológica}

En el parágrafo $\xi 37$ de su Teología del Nuevo Testamento Bultmann ya anticipaba el carácter escatológico de la fe, afirmando:

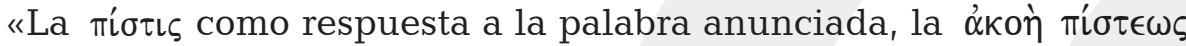
("escucha de la fe"), pertenece al acontecimiento salvífico, al acontecimiento escatológico. Es, como posibilidad, el nuevo camino de salvación $(\ldots) »^{48}$. Pero es en el parágrafo $\xi 50$ donde desarrolla el tema: «La fe como existencia escatológica». Bultmann señala las coincidencias básicas entre Juan y Pablo en lo concerniente a la importancia de la fe. Tanto para el evangelista como para Pablo «la fe es el camino hacia la salvación, el único camino. El "solamente por la fe" es tan evidente para Juan y por ello no lo subraya expresamente» ${ }^{49}$.

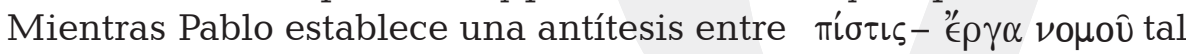
oposición no aparece en Juan pero, a su vez, Juan "a diferencia de Pablo, no discute el camino de salvación, sino la cuestión de la salvación misma (...) $»^{50}$.

Para Bultmann la fe es no solo decisión sino también obediencia. En el ensayo «gracia y libertad» explica Bultmann:

La fe es obediencia porque en ella es quebrantado el orgullo del hombre.

Lo que es propiamente evidente le resulta al hombre lo más difícil por su orgullo. No quiere arrojar la carga bajo la cual gime; se ha convertido para él en parte de su yo; más aún, en su mismo yo. Piensa que se pierde si renuncia a sí mismo; si renuncia a lo que ha hecho de sí mismo. Sin embargo, debe perderse, porque solo así puede encontrarse

47 Ibíd., 389-390. El término «decisión» también pertenece al repertorio de Heidegger que Bultmann recoge de Ser y tiempo y del período en que ambos pensadores trabajaron juntos en Marburgo. En un texto publicado después de la muerte de Heidegger vincula la decisión a la libertad. Dice: «ìPor qué tienen que producirse decisiones? ¿Qué es esto, decisión? La necesaria forma de realización de la libertad». Martín Heidegger, Aportes a la filosofía. Acerca del evento, op. cit., 94. Cursivas originales.

48 Rudolf Bultmann, Teología del Nuevo Testamento, op. cit., 389. Cursivas originales.

49 Ibíd., 493.

50 Ibíd., 393-394. Cursivas originales. 
realmente. Debe doblegarse, humillarse, despedirse de su orgullo, para llegar a sí mismo ${ }^{51}$.

Bultmann también toma en cuenta los desafíos que las ciencias naturales provocan a la fe. En su ensayo «La crisis de la fe», que data de 1931, comienza por distinguir la crisis moral de la crisis de fe, afirmando que, a pesar de que la fe se relacione con la moral, se distingue de ella

(...) porque es siempre una fe determinada, fe en un frente a, en su más allá del hombre. La fe no es religiosidad, ni una disposición de recogimiento, gratitud, veneración y respeto del alma ante el mundo y la vida como un todo, sino que comprende el mundo y la vida desde una realidad que está más allá de ellos, desde un poder que los trasciende, que es su origen y señor; desde $\operatorname{Dios}^{52}$.

Las ciencias de la naturaleza someten a la fe a una crisis que implica que el ser humano es colocado ante la cuestión de si puede comprender su ser desde la observación e investigación científicas. Pero en esa pretensión Bultmann observa, en coincidencia con Karl Barth, que allí «se oculta la pretensión del hombre de ser él mismo, de comprender y modelar su vida desde aquello de que dispone, desde lo que domina o estima dominar con el pensamiento y su acción solícita» ${ }^{53}$. Para Bultmann las crisis de la fe, provocadas por las ciencias naturales y la historia, no son cosas a rechazar sino, curiosamente, para celebrar. Explica la razón:

51 Rudolf Bultmann, «Gracia y libertad», en Creer y comprender, vol. II, op. cit., 131.

52 Rudolf Bultmann, «Crisis de la fe» en Ibíd., 7.

53 Ibíd., 18. Decimos que el lenguaje de Bultmann se parece al de Barth sobre todo si lo comparamos con el famoso parágrafo $\xi 16$, «The Revelation of God as the Abolition of Religion», en Church Dogmatics, I.2, trad. G. W. Bromiley, T. F. Torrance (Edimburgo: T \& T Clark, 1956), 280-361, donde el teólogo suizo establece una oposición tajante entre la revelación de Dios en Cristo y la religión entendida como proyecto humano, carnal y, por lo tanto, destinado al fracaso. Ese texto está disponible en castellano como libro autónomo: Karl Barth, La revelación como abolición de la religión, trad. Daniel Vidal (Madrid: Marova-Fontanella, 1973). Por supuesto que esta es una coincidencia tangencial entre ambos teólogos, ya que se sabe que Karl Barth nunca entendió el proyecto de «desmitologización» del Nuevo Testamento y hasta lo consideraba algo superfluo. Véanse las cartas entre Barth y Bultmann en: Bernd Jaspert (ed.), Correspondencia Karl Barth - Rudolf Bultmann, trad. José Arana (Bilbao: Descleé de Brouwer, 1973), especialmente 152-181. En una de esas cartas escribe Barth: «yo tengo preocupaciones distintas de Vd. Por eso también para mí todo el problema del kerigma y del mito es una cuestión de segundo orden», Carta fechada en Basilea el 24 de diciembre de 1952, Ibíd., 177. 
(...) fuerzan a reflexionar sobre la esencia de la fe y ponen de manifiesto la cuestión de la decisión a favor o en contra de la fe; la cuestión de la decisión, que no es nunca cuestión del conocimiento investigador y poseedor, sino siempre cuestión de la voluntad, de la apertura al instante, y que por lo mismo no se pude resolver con ninguna ciencia ${ }^{54}$.

La existencia escatológica se relaciona también con el hecho de que el creyente ha sido arrancado del mundo «de su ser mundano». Tomando en consideración los textos del cuarto evangelio, Bultmann relaciona el conocimiento con la libertad. Señala que ese conocimiento que da la libertad no es un conocimiento teórico, distante, sino que es «un dejarse determinar por lo conocido, un ser en lo conocido, de manera que puede designarse la relación hacia el Revelador y hacia Dios mediante un $\epsilon \hat{\imath} \nu \alpha \iota$ Ł́v ("estar en") $(15,3 s ; 17,21) »^{55}$. En cuanto a la libertad, se trata de libertad del mundo y del pecado. A partir de la expresión «guárdalos del mal» (Jn. 17.15) Bultmann aclara que «la libertad frente al pecado no consiste en hallarse dotados de

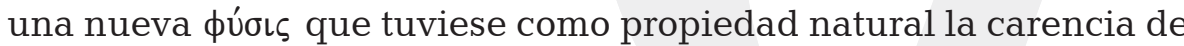
pecado. Más bien esta carencia de pecado es propia de la fe $(\ldots) »^{56}$.

Bultmann hace una referencia a la teología paulina donde destaca el problema de la relación entre el indicativo y el imperativo de la vida cristiana. Para Pablo: «La existencia escatológica está marcada

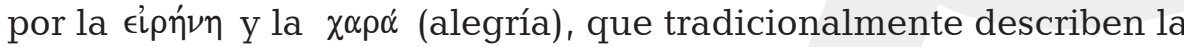
salvación escatológica (cf. Por ejemplo Rom 14,17)» ${ }^{57}$. Volviendo a la

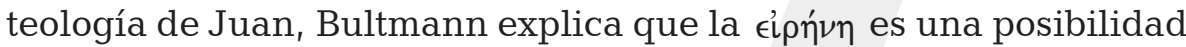
escatológica que está más allá de una mera disposición del alma ya que «solamente puede ser aprehendida como realidad por la fe y que, por ello, como tampoco la libertad, no puede convertirse en un estado o condición ${ }^{58}$ ¿En qué consiste la existencia escatológica? Siempre inspirado en la teología joanina, Bultmann define:

Se describe la existencia escatológica al presentar el ser del creyente como un estar en el Revelador, o, también, como un estar del Revelador

\footnotetext{
54 Rudolf Bultmann, "Crisis de la fe», op. cit., 19.

55 Rudolf Bultmann, Teología del Nuevo Testamento, op. cit., 497.

56 Ibíd., 498.

57 Ibíd., 501.

58 Ibíd., 501-502.
} 
en ellos, de manera que ellos entre sí y con él forman una unidad -unidad, al mismo tiempo, con el Padre, en el que está el Hijo y el cual está en el Hijo- ${ }^{59}$.

En una referencia más específica a la escatología, Bultmann entiende que las palabras de Jesús en cuanto al conocer recíproco entre Jesús y sus discípulos (Jn 10,2s, 14s y 27), proceden del lenguaje místico mediatizado por el lenguaje apocalíptico. Por otra parte, la promesa del retorno para volver a verse con ellos (Jn 14,8s, 28; 16,16s, sobre todo 14,23) son interpretados del siguiente modo:

Estas últimas palabras no hablan de una parusía realista; las otras tampoco de la relación mística entre Jesús y los suyos. Todas estas palabras describen la existencia escatológica del creyente arrancada del mundo. Esta existencia es real únicamente en la fe y no en una relación directa a Jesús o a Dios $^{60}$.

A los fines de completar la visión que Bultmann refleja sobre la existencia escatológica en su relación con el Reino de Dios y la decisión, es oportuno citar su texto Jesús que consagra el punto 2 al tema del Reino. Al intentar definir al Reino, dice Bultmann: «el reino de Dios es la salvación del hombre, esto es, la salvación escatológica que acaba con todo lo terreno» ${ }^{61}$. El énfasis de Bultmann radica en el carácter extramundano o suprahumano del Reino de Dios. Dice: «El reino de Dios, como salvación escatológica, intramundana, es la antítesis de todos los bienes relativos intramundanos $(\ldots) »^{62}$. Y agrega: «El "reino de Dios" no es algo susceptible de materializarse en la historia de los hombres (...) $)^{63}$. Pero hay dos aspectos en los cuales Bultmann refleja la influencia de Heidegger: la decisión y la muerte. El futuro y el presente se encuentran en el «trance de la decisión». Para Jesús, interpreta Bultmann, el ser humano no está determinado por ninguna cualidad innata sino por la decisión que haga en el aquí y ahora.

59 Ibíd., 503. Cursivas originales

60 Ídem. Cursivas originales.

61 Rudolf Bultmann, Jesús, trad. Pablo Simón (Buenos Aires: Sur, 1968), 31. Cursivas originales.

62 Ídem.

63 Ibíd., 33 
Hay, pues, una analogía con eso de entender la esencia humana caracterizada por el inexorable enfrentamiento del hombre con el destino y la muerte y la forma en que él se deja determinar por estas dos potencias. Y en efecto, el reino de Dios y la muerte se parecen en cuanto también el primero significa el fin de la existencia terrenal del hombre, la única que conocemos, con sus posibilidades y sus intereses; y puede decirse que la muerte, igual que el reino de Dios, no entra en consideración para el hombre como acontecimiento fortuito que en su hora pondrá fin al curso temporal de la vida, sino como futuro verdadero que se presenta ante cada decisión y, así, lo determina en su presente, situándolo ante la decisión ${ }^{64}$.

Se puede apreciar que el enfoque bultmanniano del Reino de Dios queda confinado a una cuestión intimista y personal: significa simplemente la «salvación» del ser humano en un plano extramundano. Bultmann no ofrece ninguna perspectiva de una materialización del Reino en el mundo, simplemente significa una salvación escatológica de índole individual para la cual la decisión es la clave de acceso. En la conclusión nos ocuparemos de analizar críticamente esta perspectiva escatológica de Bultmann. Ahora, habiendo expuesto lo que Bultmann entiende por la fe como acontecimiento escatológico y su concepto del Reino, pasamos a analizar su planteo teológico para detectar en qué aspectos su pensamiento, si bien está impulsado por la filosofía de Heidegger, representa un desarrollo más amplio sobre el tema.

\section{El planteo teológico de Bultmann}

Es cierto que Bultmann se muestra influido por el pensamiento filosófico de Heidegger. Términos como "decisión», "angustia», «desesperación», «caída» son usados tanto por Heidegger como por Bultmann. Pero ¿̇hasta qué punto este último simplemente pone en «lenguaje cristiano» las incisivas fórmulas de Heidegger? Sobre todo, ¿cuál es el objetivo último de Bultmann sobre la fe, a partir de ese diálogo con el filósofo existenciario?

Como expresamos en la introducción de este trabajo, muchos lectores de Bultmann rechazan su teología al quedar espantados por 
su propuesta de la «desmitologización», no siempre bien entendida. Pero el verdadero tema de Bultmann no es ese, sino que su propósito es que, mediante un proceso hermenéutico que él denomina «desmitologización», el kerigma pueda suscitar la fe del hombre moderno. En este punto, es bueno tener en cuenta las observaciones de Juan Luis Segundo cuando se refiere a la «desmitologización». El tema aparece en el capítulo V de El hombre de hoy ante Jesús de Nazaret, II/2, titulado «desmitologización y espíritus» y en un contexto donde el teólogo uruguayo se refiere a los «ejercicios espirituales». Segundo resume lo que Bultmann quiere decir con «mito», bajo tres aspectos: a. Una experiencia subjetiva de un encuentro con lo absoluto, b. una causalidad sobrenatural que opera como causa natural y c. una historia «sagrada» donde se tomen en cuenta y se narran interrupciones de la historia profana. A continuación aclara:

\begin{abstract}
(...) la palabra «desmitologización» es engañosa, pues Bultmann no propone desembarazarse sin más de toda narración «mítica». Lo que propone es interpretarla. Y, para ello, volver a poner en el interior, en lo «existencial», lo que el mito proyectó al exterior, al reino de los objetos y acontecimientos objetivos. Así el hecho, si no el acontecimiento, conserva su valor decisivo y aun teológico ${ }^{65}$.
\end{abstract}

Pero donde mejor se observa la mayor influencia de Heidegger sobre Bultmann es en cuanto al círculo hermenéutico, a partir del cual el lector u oyente del kerigma alcanzará una mejor comprensión de sí mismo, lo cual derivará en la «vida auténtica». Segundo desliza cierta duda en cuanto a si Bultmann entiende bien a Heidegger, aunque destaca lo importante de esa influencia:

Ese camino, como se sabe, es un análisis hecho por Heidegger en su conocida obra El ser y el tiempo de las diferencias entre una existencia inauténtica y una auténtica. Prescindamos del problema de si Bultmann entiende bien o no a Heidegger. Este tiene una intención ontológica que Bultmann descarta pretendiendo que si no buscamos en Heidegeer los resultados de un análisis existenciario, sino existencial (de acuerdo a la terminología adoptada por el traducir castellano), hallaremos en El ser

65 Juan Luis Segundo, El hombre de hoy ante Jesús de Nazaret, II/2 (Madrid: Cristiandad, 1982), 720.

Cursivas originales. 
y el tiempo un análisis metódico muy útil para ahondar y perfeccionar nuestro nivel de comprensión existencial ${ }^{66}$.

A la luz de esta interpretación sobre la desmitologización, podemos decir que esa tarea no es para Bultmann un fin en sí mismo. Se trata siempre de un método para llegar a un fin: que el oyente pueda captar el sentido del kerigma y, con él, alcanzar la «vida auténtica». Como explica Ricoeur: «La filosofía de Heidegger proporciona solamente el requisito filosófico previo para una crítica del mito, cuyo centro de gravedad es el proceso de objetivación ${ }^{67}$. Como había afirmado antes el filósofo francés: «Separar el kerigma del mito es la función positiva de la desmitologización» ${ }^{68}$. Luego aclara que hay que distinguir en Bultmann tres «personalidades» que adopta: como hombre de fe, como filósofo y como auditorio de la palabra, dice Ricoeur:

\begin{abstract}
Cuando se sitúa en este último círculo, predica. Sí, predica; hace escuchar el Evangelio. De este modo, como discípulo de Pablo y de Lutero, opone la justificación por la fe a la salvación por las obras; por las obras, el hombre se justifica y se glorifica, es decir, dispone, en tanto soberano, del sentido de su existencia; en la fe, se desprende de la pretensión de disponer de sí mismo ${ }^{69}$.
\end{abstract}

Precisamente en esa crítica que Bultmann formula a la pretensión humana de «disponer de sí mismo», de «autojustificarse» y «glorificarse» donde encontramos otro distanciamiento del planteo de Heidegger. Si bien tanto en este último como en Bultmann el ser humano es una «posibilidad»y alcanzar «la vida auténtica» es una posibilidad, para Bultmann la misma nunca se podrá alcanzar mediante el esfuerzo humano, por más hercúleo que fuese. Comenta René Marlé:

La existencia en la fe es por el contrario una existencia fundada en lo invisible que el hombre no tiene en su propio poder, una existencia que renuncia, de antemano, a cualquier seguridad procurada por la industria humana. Una vida así no se hace «posibilidad» para el hombre si no es

\footnotetext{
66 Ibíd., 721. Cursivas originales.

67 Paul Ricoeur, «Prefacio a Bultmann», El conflicto de las interpretaciones, op. cit., 352.

68 bíd., 351.

69 Ibíd., 353-354.
} 
por la fe en la «gracia» de Dios, es decir, por la confianza que el hombre tiene en encontrarlo invisible, lo desconocido, bajo la forma de un amor que le abre un porvenir que es, precisamente, la vida misma ${ }^{70}$.

Bultmann tomó muy en serio el desafío filosófico planteado por Heidegger y lo aplicó al terreno decididamente teológico. Desde el planteo «existenciario» de Heidegger, encaró un proyecto de envergadura: articular la teología cristiana teniendo como eje la fe como evento que acontece cuando el ser humano es confrontado con el kerigma y el verdadero escándalo: la cruz de Cristo. Una fe que es decisión y obediencia pero que, en su propia esencia, toca al ser humano en su propia existencia y facticidad. En palabras de Capelle-Dumont:

Bultmann «pone de manifiesto» de algún modo en teología la atención filosófica de Heidegger a la experiencia facticial y su carácter histórico, pero ello, aún más y mejor que el modelo a partir del cual Heidegger se pregunta por la vida facticial, y esto es, se ha señalado, la experiencia cristiana... ${ }^{71}$.

Se puede afirmar que la filosofía de Heidegger ha servido a Bultmann para reinterpretar la situación humana en el siglo XX. El punto de coincidencia mayor está dado en el diagnóstico que esa filosofía hace de Dasein, el -ser-ahí que es arrojado al mundo-. Él comenta su influencia: «Heidegger puede exhortarnos a la resolución de existir como yo mismo de cara a la muerte, porque nos abre los ojos a nuestra situación como la de "arrojados" en la Nada» ${ }^{72}$. Pero ese punto de coincidencia no debe despistarnos de lo que realmente plantea Heidegger. En el parágrafo $\xi 50$ de Ser y tiempo, Heidegger

René Marlé, Bultmann y la fe cristiana, trad. José Manuel Maruri (Bilbao: Mensajero, 1968), 72-73. Philippe Capelle-Dumont, op. cit., 233.

Rudolf Bultmann, Nuevo Testamento y mitología, op. cit., 45. Cursivas originales. Respecto a la expresión de Heidegger «ser-para-la-muerte», Vattimo interpreta que entre todas las posibilidades o potencialidades del Dasein la más cierta es la muerte, hecho atestiguado en que todos morimos, «es decir, que esa posibilidad es coesencial al Dasein, pero la raíz del hecho empírico de que todos mueren es la circunstancia de que la muerte es la posibilidad más propia del Dasein en cuanto lo afecta en su mismo ser, en su esencia misma de proyecto, mientras que cualquier otra posibilidad se sitúa en el interior del proyecto mismo como su modo de determinarse». Gianni Vattimo, Introducción a Heidegger, trad. Alfredo Báez (Barcelona: Gedisa, 1986), 48. El «ser-para-la-muerte» implica a la muerte como sumo y extremo testimonio, como medición extrema de la temporalidad del Dasein. Martín Heidegger, Aportes a la filosofía. Acerca del evento, op. cit., 231-233. 
describe la «caída» del Dasein y su condición de arrojado. El término «caída» no es usado por Heidegger en el sentido teológico que supone haber perdido su estado natural, sino que «ha caído en el mundo, en ese mismo mundo que forma parte de su ser. La caída es una determinación existencial del Dasein mismo, y no dice nada acerca del Dasein en cuanto ente que está ahí, o acerca de relaciones simplemente presentes con algún ente del cual pudiera "proceder" (...) $»^{73}$. Porque, mientras para Heidegger esa «caída» es algo neutral, para Bultmann es justamente la situación desesperada del ser humano sin la fe en Cristo:

El punto en cuestión es cómo entendemos la caída. Incluso los filósofos están de acuerdo al respecto. Pero piensan que todo cuanto necesita el hombre es que le muestren su situación y entonces podrá escapar de ella. En otras palabras, la corrupción resultante de la caída no se extiende al núcleo de la personalidad humana. El Nuevo Testamento, por otra parte, considera la caída como total ${ }^{74}$.

En un aspecto, Bultmann no ha entendido bien a Heidegger en cuanto a la "caída» pero, en otro, lo interpreta adecuadamente cuando dice que el Dasein es arrojado al mundo y, finalmente, a la Nada.

\section{Conclusión}

Bultmann recibe de Heidegger un inicial impulso para elaborar una teología para el siglo XX, en un ámbito filosófico dominado por el existencialismo. Pero desde ese influjo va más allá de Heidegger para articular una teología en torno al tema de la fe. Mientras la teología fue una primera inspiración para Heidegger para derivar después, decididamente, a un planteo filosófico "existenciario», Bultmann hace suyo el desafío de Heidegger para derivar a una teología existencial, cuyo eje es la fe en Jesucristo como centro del kerigma. En otras palabras, ambos pensadores recorren un trayecto inverso: mientras Heidegger comienza con la teología, deriva luego decididamente a la filosofía existenciaria, mientras que Bultmann recibe el impulso inicial de esa misma filosofía, pero luego la trasla-

73 Martin Heidegger, Ser y tiempo, op. cit., 219. Cursivas originales.

74 Rudolf Bultmann, Nuevo Testamento y mitología, op. cit., 47. 
da al plano teológico con la fe como objeto central y neurálgico de su proyecto. En otras palabras, Bultmann ha tenido la capacidad de teologizar los conceptos filosóficos de Heidegger.

Cuando Bultmann dice que la fe en Dios significa la llamada al instante, como la exigencia del tú que me sale al encuentro, como la llamada al amor, entonces la crisis de la fe cristiana en Dios es siempre a la vez la crisis del amor. Las palabras «instante», «exigencia», «decisión», «encuentro», «crisis», «posibilidad», «acontecimiento», «evento», pertenecen al vocabulario del existencialismo y han sido teologizadas por Bultmann para señalar que la fe no es algo estático e irrepetible, sino que es un evento que acaece en el instante de la decisión, pero que también debe ser realizado siempre de nuevo.

Creemos haber demostrado que el verdadero interés de Bultmann no es la «desmitologización». Su verdadero foco de atención es la fe que se ve obturada por la mitología precientífica del Nuevo Testamento. La desmitologización era solo un método que propone para facilitar que el kerigma pueda interpelar al hombre moderno.

Al definir a la fe como un evento escatológico, de alguna manera Bultmann se sitúa en una especie de «escatología realizada» ${ }^{75}$ o, quizás mejor, una escatología existencial que significa que el ser humano, al ser confrontado con el kerigma, está en el último acto de decisión.

La escatología bultmanniana se mueve en un plano casi exclusivamente intimista y espiritual, al punto de negar lo que se denomina una «escatología realista». En ese contexto, inclusive, destaca tanto a la fe en sí misma, al punto de negar que se refiera a una relación directa con Jesús o con Dios. Estos son, quizás, los puntos más cuestionables del planteo de Bultmann, en cuya teología parece no haber lugar para una visión cósmica de la redención. Las críticas a ese planteo han procedido tanto de la teología europea como de la teología latinoamericana. En su obra sistemática de escatología The coming of God, Moltmann critica ese punto de 
vista, señalando que la interpretación existencial que Bultmann desarrolla sobre la escatología es correcta en su concentración de la propia existencia individual, pero no nos ayuda con respecto a la historia del mundo y de la naturaleza. «Reemplazar la historia del mundo por la historicidad de la existencia no hace desaparecer de la historia del mundo. Percibir el futuro como futuridad individual no dispersa el futuro» ${ }^{76}$.

Con referencia a los teólogos latinoamericanos, solo nos permitimos citar a dos de ellos: Jon Sobrino y Ricardo Foulkes. El primero, aunque admite que Bultmann es un fuerte defensor de la escatología, la ha enfocado exclusivamente en el Jesús de los evangelios y no desde la perspectiva del Reino de Dios. De ese modo, todo el énfasis recae en la existencia individual que debe ser auténtica, abierta y liberada, pero «sin referencia esencial a la exterioridad del ser humano y a la transformación de la historia» ${ }^{77}$. Y agrega sin ambages: «La escatología de Bultmann es, por lo tanto, a-social y nada tiene que ver con la construcción del reino de Dios; es también a-temporal y nada tiene que ver con un futuro que pudiese convertirse en plenitud $\iota^{78}$.

Por su parte Ricardo Foulkes señala que, en su gran mayoría, los teólogos latinoamericanos no se han sentido atraídos por el sistema de Bultmann y explica:

Las experiencias existenciales de guerras, desnutrición y dominación imperialista, les han convencido que un sistema que protagoniza casi exclusivamente al individuo y sus decisiones, no ha captado la esencia del evangelio. Gustavo Gutiérrez resume esta reacción cuando comenta: «La desmitologización es un proyecto imposible». Parece que la filosofía de Heidegger no es el mejor odre donde guardar el vino del evangelio. Y es precisamente nuestra experiencia en América Latina -que es por definición más colectiva que intimista-, la que demuestra la deficiencia

76 Jürgen Moltmann, The Coming of God. Christian Eschatology, trad. Margaret Kohl (Minneapolis: Fortress Press, 1996), 20-21.

77 Jon Sobrino, Jesucristo liberador. Lectura histórica-teológica de Jesús de Nazaret (San Salvador: UCA, 1991), 193.

78 Ibíd., 195. 
de un esquema forjado en medio de la abundancia. Nuestra lectura de la Biblia es otra ${ }^{79}$.

Por otra parte, la escatología de Bultmann significa un reduccionismo a la perspectiva neotestamentaria sobre el tema. De alguna manera para él es cierto que la fe entra en la historia pero, en todo caso, lo hace para poner fin a ella. En palabras de Joseph Florkowski:

\begin{abstract}
Cuando habla de la fe y del hecho escatológico de Cristo, se deduce claramente que para él la escatología es la única forma de lo eterno que puede alcanzar la historia. Y lo propio de la escatología es poner fin a la historia, pero poner fin ya en la actualidad presente y cada vez que se revela en la predicación de la palabra de $\operatorname{Dios}^{80}$.
\end{abstract}

Pese a todas esas limitaciones y reduccionismos, sobre todo en lo que tiene que ver con la escatología y el futuro del mundo, el pensamiento de Bultmann sobre la fe es una invitación a pasar de la crisis en que las ciencias naturales y la historia han colocado a la fe, a una crisis en el sentido de la fe como decisión existencial y escatológica, convirtiendo el instante temporal en instante eterno. Parafraseando a Kant cuando dijo «tuve que dejar de lado la razón para dar lugar a la fe», Bultmann parece decirnos: «tuve que dejar de lado el mito para dar lugar a la fe». Y para que esa fe surja de la interpelación del hombre moderno, propone la desmitologización para que el falso escándalo dé lugar al verdadero escándalo: la cruz de Cristo.

\title{
Bibliografía
}

Agamben, Giorgio. Teología y lenguaje. Del poder de Dios al juego de los niños. Traducido por Matías Raia. Buenos Aires: Las Cuarenta, 2012.

Astrada, Carlos. Heidegger. De la analítica ontológica a la dimensión dialéctica. Buenos Aires: Quadrata, 2003.

79 Ricardo Foulkes, «Rudolph Bultmann» en Franz J. Hinkelammert, et. al., Teología alemana y teología de la liberación. Un esfuerzo de diálogo (San José: DEI, 1990), 83.

80 Joseph Florkowski, op. cit., 176. Para un análisis más pormenorizado de la escatología bultmanniana, véase Alberto F. Roldán, Escatología: una visión integral desde América Latina (Buenos Aires: Kairós, 2002). 
Barth, Karl. Church Dogmatics, I.2. Traducido por G. W. Bromiley, T. F. Torrance. Edimburgo: T \& T Clark, 1956. . La revelación como abolición de la religión. Traducido por Daniel Vidal. Madrid: Marova-Fontanella, 1973.

Bowden, John y Richmond, James. Antología de teólogos contemporáneos. Traducido por José Luis Lana. Barcelona: Kairós, 1967.

Bultmann, Rudolf. Creer y comprender, vol. I y II. Traducido por D. Eloy Requena. Madrid: Stvdivm, 1974 y 1976.

. Existence \& Faith. Shorter Writings of Rudolf Bultmann. Nueva York: Meridian Books, 1960.

. Kerygma und Mythos. Hamburg: Reich \& Heidrich, 1960. - Nuevo Testamento y mitología. Traducido por Antonio Bonnano. Buenos Aires: Almagesto, 1998.

- Teología del Nuevo Testamento. Traducido por Víctor A. Martínez de Lapera. Salamanca: Sígueme, 1981.

Bultmann, Rudolf y Jaspers, Karl. Jesús. Traducido por Pablo Simón. Buenos Aires: Sur, 1968.

Bultmann, Rudolf y Weiser, Arthur. Faith. Bible Key Word from Gerhard Kittel's. Traducido por Dorotea M. Barton. Londres: Adam \& Charles Black, 1961

Capelle-Dumont, Philippe. Filosofía y teología en el pensamiento de Martin Heidegger. Traducido por Pablo Corona. Buenos Aires: FCE, 2012.

Corona, Néstor. Lectura de Heidegger. La cuestión de Dios. Buenos Aires: Biblos, 2002.

Dodd, C. H. Las parábolas del reino. Madrid: Cristiandad, 1965.

Etchegaray, Ricardo. Introducción a los modelos de pensamiento dialéctico, fenomenológico, hermenéutico y existencial, vol. 2. Buenos Aires-San Justo: Universidad Nacional de la Matanza-Prometeo Libros, 2007. 
Florkowski, Joseph. La teología de la fe en Bultmann. Traducido por D. Eloy Requena. Madrid: Stvdivm, 1973.

Foulkes, Ricardo. «Rudolph Bultmann». En Franz J. Hinkelammert, at. al. Teología alemana y teología de la liberación. Un esfuerzo de diálogo. San José: DEI, 1990.

Greisch, Jean. La invención de la diferencia ontológica. Heideger después de Ser y Tiempo. Traducido por Julián Fava. Buenos Aires: Las Cuarenta, 2010.

Gromann, Andreas y Landmesser, Christof, eds. Rudolf Bultmann/ Martin Heidegger. Correspondencia 1925-1975. Traducido por Raúl Gabás. Barcelona: Herder, 2012.

Heidegger, Martín. Aportes a la filosofía. Acerca del evento. Traducido por Dina V. Picotti C. Buenos Aires: Biblos, 2006.

- Fenomenología de la religión. Traducido por Jorge Uscatescu. México: Siruela-FCE, 2006.

. Hitos. Traducido por H. Cortés Gabaudán y A. Leyte Coello. Madrid: Alianza, 2000.

. Introducción a la fenomenología de la religión. Traducido por Jorge Uscatescu. México: Siruela-FCE, 2006.

. Ontología. Hermenéutica de la faticidad. Traducido por Jaime Aspiunza. Madrid: Biblioteca Nacional, 2003.

. Ser y tiempo. Traducido por Jorge Eduardo Rivera. Madrid: Editora Nacional, 2002.

. Wegmarken. Fránfort del Meno: Klostermann, 1978.

Jaspert, Bernd, ed. Correspondencia Karl Barth - Rudolf Bultmann. Traducido por José Arana. Bilbao: Descleé de Brouwer, 1973.

Löwith, Karl. Heidegger, pensador de un tiempo indigente. Sobre la posición de la filosofía en el siglo XX. Traducido por Román Setton. Buenos Aires: FCE, 2006. 
Macquarrie, John. An Existencialist Theology: A comparison of Heidegger and Bultmann. Londres: SCM Press, 1955. . Martin Heidegger. Londres: Lutterworth Press, 1968.

Maldonado, Luis. El menester de la predicación. Salamanca: Sígueme, 1972.

Marlé, René. Bultmann y la fe cristiana. Traducido por José Manuel de Maruri. Madrid: razón y fe, 1968.

Moltmann, Jürgen. The coming of God. Chistian Eschatology. Traducido por Margaret Kohl. Minneapolis: Fortress Press, 1996.

Picotti, Dina C. Heidegger. Una introducción. Buenos Aires: Quadrata, 2010.

Ricoeur, Paul. «Prefacio a Bultmann». En El conflicto de las interpretaciones. Traducido por Alejandrina Falcón. Buenos Aires: FCE, 2003.

Roldán, Alberto F. Escatología: una visión integral desde América latina. Buenos Aires: Kairós, 2002.

. «La reivindicación del prejuicio como precomprensión en la teoría hermenéutica». Enfoques 1, año XXIV (2012): 19-29.

Segundo, Juan Luis. El hombre de hoy ante Jesús de Nazaret, II/2. Madrid: Cristiandad, 1982.

Sobrino, Jon. Jesucristo liberador. Lectura histórica-teológica de Jesús de Nazaret. San Salvador: UCA, 1991.

Vallés, Alejandro. Nota preliminar a Martín Heidegger, ¿Qué es metafísica? Traducido por Xavier Zubiri. Buenos Aires: Ediciones Alpe, 1955.

Vattimo, Gianni. Ética de la interpretación. Traducido por Teresa Oñate. Barcelona: Paidós Ibérica, 1991. . Introducción a Heidegger. Traducido por Alfredo Báez. Barcelona: Gedisa, 1986. 